\title{
New Tendencies in the Development of Modern English
}

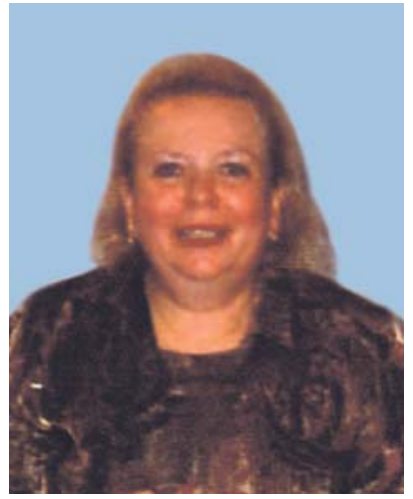

Olga Alexandrova
7 he second half of the 20th century was approaches in language studies. E.S. Kubriakova singles out four main features of linguistics in the 20th century: functionalism, anthropocentrism, expansionism, and explanatory character. ${ }^{1}$ It is a well-known fact that language is an indispensable part of a human being, it lives and develops together with him and the surrounding world. In general, science developed dramatically in the 20th century, together with the rising interest in language as one of the main means of communication. Furthermore, the need to categorize the external world grew considerably. The integration and cooperation of different scientific trends required language to be treated as a multisided phenomenon, which was directly connected with such branches of human knowledge as the theory of communication, pragmatics, semiotics, the theory of politeness, anthropology, sociology and many others. The main characteristic feature of linguistic research now is the study of the functional peculiarities of linguistic units, and the importance of understanding how to use different linguistic units in different communicative situations. In this respect, it is not only purely linguistic factors that are important, but also many different aspects of the extralinguistic context.

The functional approach to the study of language is not clearly defined yet, though the majority of linguists emphasise the importance of this approach for modern linguistics. In very many respects this is connected with the already established postulates in linguistics, which recognize the relative stability of the grammatical system. The latter has a lot of common features in different languages and changes more slowly than any other part of the language.

Functionalism is characteristic of typologically oriented linguistics, assisting in the handling of the corpus of data and allowing attention to be given to data from other branches of knowledge, which are important for linguistic study, especially on the interdisciplinary level.

The last decades of the 20th century and the beginning of the 21st century are characteristic of a new trend in linguistics - the cognitive approach to the study of language. It has become possible to understand the utterance and its role in the text on 
the basis of a wider background of discourse. Discourse studies are usually done on a textual basis, but until now it has been difficult to speak about some of the generating potential of discourse which may be characteristic of different texts belonging to different functional styles. In the present paper the term "discourse" is used to emphasise the dynamic character of the texts under investigation. The meaning of this term is discussed by many linguists (and not only linguists), and it is differently defined by different scholars. Naturally, it is not a new phenomenon in linguistics. Initially, it was applied to oral speech. It first appeared in American linguistics and was probably introduced because linguists wanted to go beyond the limits of the isolated sentence.

Nowadays this term is used in much a wider sense, in reference to speech in particular. The peculiar feature of discourse is that it presupposes two-sided communication: first of all, it is directed at some specific receiver and has a sender who has certain subjective characteristics reflecting his social status.

A great number of factors are involved in the process of discourse creation: social, communicative, pragmatic, cultural, historical and so on. There may be political, artistic, musical, theatrical and other types of discourse. In recent years scholarly attention has been focused on a new type of discourse - Internet texts. Users know that it is possible to find different kinds of texts on the Internet: fiction, academic writing, mass media practically all possible existing types. Of special interest is communication between people within the Internet itself. So-called electronic language is attracting more and more attention from linguists, who are concerned with its possible influence on language in general. Of course, the priority in this respect should be given to the English language: it is the first language of the Internet and its use is spreading. Its presence in the Internet supports its position as the primary language for international communication: a great many words which were introduced into the English language with the development of computer systems have now been borrowed by other languages, and language has acquired a codified system of units. Linguists are also concerned with the influence this system may have on the living language. It is known that similar apprehensions existed in connection with the development of printing, the telephone, radio and television.

Sometimes Internet language is compared to artificial languages, like Volapuk or Esperanto. But the great difference consists in the fact that English is a living language and had already been the language of international communication by the time the Internet appeared. Internet language is based on this living language - English - or to be more exact, American English.

Some linguists suggest that the Internet, in conjunction with radio and television, telephone communication and printed materials, has created a universal information net, which they call "cyberspace", and that all of us are the "netizens" in this net (the word is easily associated with "citizens"). The language we use in the Internet is "netspeak" and the corresponding derivations - "Netlish" and "Weblish" (easily associated with English), or electronic discourse, interactive written discourse, etc. ${ }^{2}$

Here a very important question arises: for many years linguists have been discussing the interrelationship between oral and written speech. It is accepted that oral speech is primary, and that written speech changes under the influence of oral speech. Some 
features which were assumed to be ungrammatical formerly and were considered to be peculiar to oral speech, have now become the grammatical norm. Take, for example, nominative, And- and But- sentences, ellipsis, etc., which until recently were beyond the limits of normative English Grammar.

The language of the Internet combines oral and written speech: there are more or less normalized materials, but at the same time there is communication - online chatrooms, e-mails and e-worlds, which presuppose some response from those to whom they are addressed. There is a great difference within the two-sided communication in the Internet: there may be an immediate response, an indirect response, or no reaction at all, it may take time to receive the answer, and so on. Also, when communicating orally, participants are united by the extralinguistic situation. In the case of Internet communication such a context is out of the question, while in oral communication it is impossible to react to the message without mimics or gesture, but as we shall see later, the situation has changed even here.

The phenomenon of the Internet is not simply a technological fact, it is also a social fact, in which language plays the most important role. And one can see again how language reflects changes in people's everyday lives, and how these changes in language are reflected in turn in people's lives.

Do these changes mirror the changes in the human mind which are going on now, i.e. the changes in our cognitive picture of the world? For example, in Internet communication, as well as in mobile phone text messaging, it has become quite usual to create messages in the form of a peculiar kind of slang, where the forms of the words are minimized, a large number of abbreviations are used, and numerals combined with words may be present. There is also a system of signs to show accompanying emotions. People are even taught how to write and decodify this kind of message. Thus, in one of the recently published textbooks students are asked to decode the following message:

\author{
Man: $\quad$ DO U WAN2 C ME L8R 4 A DRINK? \\ Woman: WOT RU TRYING 2 SAY? \\ Man: ILUVU \\ Woman: OIC : $O$ \\ Man: $\quad P C M$ \\ Woman: IM W/ SOME1 \\ Man: WOT ABOUT YR FRIEND? I LUV HER 2. IS \\ SHE W/ NE 1? \\ Woman: I H8 $U^{3}$
}

This actually means:

Man: $\quad$ Do you want to see me later for a drink?

Woman: What are you trying to say?

Man: I love you. (Happiness)

Woman: Oh I see. (Surprise) 


\author{
Man: $\quad$ Please call me. \\ Woman: I am with someone. (Sadness) \\ Man: What about your friend? I love her too. \\ Is she with anyone? \\ Woman: I hate you.
}

An incident that happened in a British school shows the influence of mobile technologies on the way people formulate their ideas in written speech. A thirteen-yearold schoolgirl was asked to write a composition about her recent holidays. One can only imagine the surprise of the teacher when she saw the following text:

My smmr hols wr CWOT. B4 we used 2 go 2 NY 2C my bro, his GF @ THR 3:- kids FTF. ILNY, it’s gr8 plc.

Translated into "normal” language it would run as follows:

My summer holidays were a complete waste of time. Before we used to go to New York to see my brother, his girlfriend and their three screaming kids face to face. I love New York. It's a great place!

In these cases we may observe that when the borderline between oral and written speech is practically erased, there is a kind of imitation of oral speech in writing. This is especially true of chats, e-mails and mobile messages, which contain a lot of misprints, violations of grammatical rules, etc.

It is interesting to note that the word Internet itself appeared only in 1994, and in 1998 it was already listed in dictionaries. It is really surprising how quickly it became a part of the vocabulary. It was borrowed by the Russian language without any change of form and, although according to the spelling rules we expect to have the initial small letter, it is used with the capital letter. Internet slang is widely used nowadays all over the world. It has become international, internet words have been borrowed by many languages. Thus, in the Russian language such elements as 'see you' or 'e-mail' are quite common now. Such words as 'file', 'portal', 'sight', 'server' and many others are quite normal even to the ear of the philologist, and Russified computers do not reject them as being alien to the Russian language.

It is a well-known fact that English punctuation is more semantic-stylistic than logical, especially as compared with the strict Russian system of punctuation, but even this strict system of punctuation is very often violated in electronic texts. Linguists think that this neglect of punctuation may lead to some deplorable consequences. Here I would like to refer to the definition of punctuation given by Lynn Truss in her recently published book: "Punctuation has been defined in many ways. Some grammarians use the analogy of stitching: punctuation as the basting that holds the fabric of language in shape. Another writer tells us that punctuation marks are the traffic signals of language: 
they tell us to slow down, notice this, take a detour, and stop. I have even seen a rather fanciful reference to the full stop and comma as "the invisible servants in fairy tales the ones who bring glasses of water and pillows, not storms of weather or love.” But best of all, I think, is the simple advice given by the style book of a national newspaper: punctuation is 'a courtesy' designed to help readers to understand a story without stumbling." 4

The author gives many interesting examples of the neglect of punctuation and comments on its disastrous effect. For example, here is a headline in a newspaper: 'Dead sons photos may be released', where the apostrophe is left out. The title of Lynne Truss's book is: 'Eats, Shoots and Leaves'. It may sound strange unless you know the anecdote:

"A panda walks into a café. He orders a sandwich, eats it, then draws a gun and fires two shots in the air.

'Why?' asks the confused waiter as the panda makes towards the exit.

The panda produces a badly punctuated wildlife manual and tosses it over his shoulder.

'I am a panda,' he says at the door. 'Look it up.'

The waiter turns to the relevant entry and, sure enough, he finds an explanation:

'Panda. Large black-and-white bear-like mammal, native to China. Eats, shoots and leaves."”

The question of Internet discourse is increasingly attracting the attention of linguists, but these are only the first attempts to understand this new phenomenon. It will be important for the further development of languages, the English language in particular, and of linguistic policies in general, which are directly connected with the life of society and its future.

A well-known British linguist David Crystal asks the rhetorical question: "Will the electronic revolution bring revolutionary changes into the language?” There is every reason to think that the answer is positive. The phenomenon of Internet discourse may drastically change our understanding of language. Internet language, although closely connected with oral and written speech, is an absolutely new phenomenon. There is no doubt that its communicative and cognitive importance will grow. Does it endanger the development of languages such as English or Russian? Scholars who have dealt with this problem take the opposite view: it will enhance the development of languages, it will enable languages to reflect the peculiarities of the new discourse, thereby reflecting a true picture of the world.

It would be most regrettable to read this in future: 
MI DEER JO I OPE U R KRWITE WELL I OPE I SHAL SON B HABELL 42

TEEDGE U JO AN THEN WE SHORL B SO GLODD AN WEN I M PRENGTD 2 U JO WOT LARX AN BLEVE ME INF XN PIP.

which is, in fact, the writing of infant Pip in "Great Expectations”.

My dear Joe,

I hope you are quite well. I hope I shall soon be able to teach you, Joe - and then

we shall be so glad. And when I am apprenticed to you, Joe: what larks!

Believe me, in affection, Pip

\section{References:}

1. Кубрякова Е.С. Эволюция лингвистических идей во второй половине 20 века (опыт парадигмального анализа). В кн.: Язык и наука конца 20 века. М., 1995.

2. Crystal, David. Language and the Internet. Cambridge, 2001.

3. Jones, V., Kay, S. Inside Out / Upper Intermediate. Macmillan, 2002.

4. Truss, Lynn. Eats, Shoots and Leaves. The Zero Tolerance Approach to Punctuation. Profile Books, 2003, p.7.

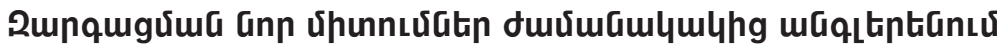

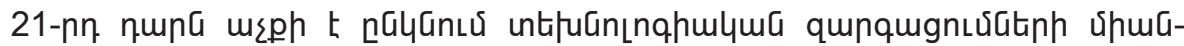

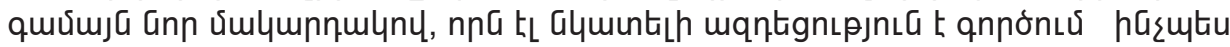

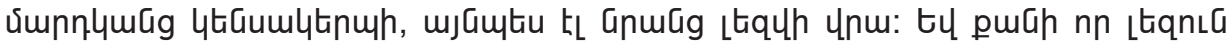

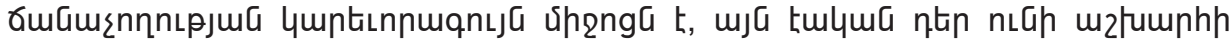

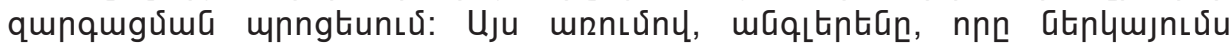

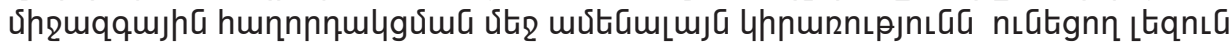

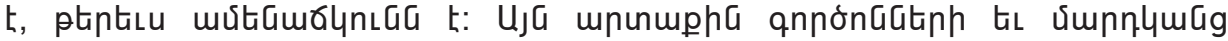

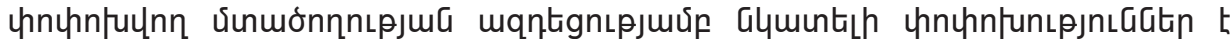

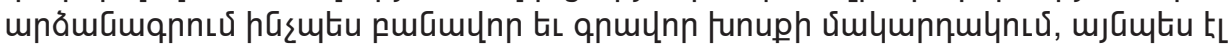
Łtrquh hurumlumpntư: 